\title{
Effect of Fibre Aspect Ratio on Mechanical Properties of Soil Building Blocks
}

\section{Humphrey Danso $\underline{a}, \underline{b}$,}

\section{Brett Martinson $\underline{a}$,}

Muhammad Ali a,

$\underline{\text { John Williams }} \underline{a}$

a School of Civil Engineering and Surveying, University of Portsmouth, Portland Building, Portland Street, PO1 3AH, United Kingdom

b Department of Construction \& Wood Technology Education, University of Education Winneba, P. O. Box 1277, Kumasi, Ghana

\begin{abstract}
Inclusion of fibres in soil blocks has been shown to enhance strength development. This study investigates the effect of aspect ratio of coconut, bagasse and oil palm fibres on the mechanical properties of soil blocks. Experiments were conducted on soil blocks with fibre aspect ratios (25125) to determine the compressive and tensile strength of the blocks. Blocks with coconut and oil palm fibres showed increasing strength with increase aspect ratio, while bagasse fibres showed an initial increase followed by a decline at higher aspect ratio. The study concludes that generally longer aspect ratios produce better mechanical properties of soil blocks.
\end{abstract}

Keywords: soil blocks, agricultural waste fibres, compressive strength, splitting tensile strength, aspect ratio

\section{Introduction}

Enhancement of the engineering properties of soil blocks with agricultural waste fibres has potential to produce more robust and resilient homes for some poorest communities in Less Economically Developed Countries (LEDCs). A range of fibres such as chopped barley straw, 
processed waste tea, vegetal, oil palm empty fruit bunches, lechuguilla, pineapple leaves, cassava peel and hibiscus cannabinus have been investigated as stabilisers to enhance the properties of soil blocks/bricks by Bouhicha, Aouissi [1], Demir [2], Achenza and Fenu [3], Kolop, Haziman [4], Juárez, Guevara [5], Chan [6], Villamizar, Araque [7] and Millogo, Morel [8] respectively. In all these studies, there were improvements in the engineering properties of the stabilised soil blocks/bricks over the unstabilised with compressive strength, for example, showing improvements varying from $4 \%$ to $117 \%$ (median of 26\%) [9]. This makes natural fibres an attractive low cost stabilising material for soil blocks. Besides the structural benefits, they also have economic, environmental and social significance when used to stabilise soil blocks for earthen construction. Thou the moisture uptake of natural fibres is high [10], the use of the fibres has generated much interest due to their low cost, low density, biodegradability, renewability and abundance [11].

The energy requirement and the processes involved in manufacturing soil blocks are less intensive than for cement, sandcrete blocks and burnt brick production and therefore soil blocks have a less environmental impact [12-15]. Furthermore, soil is locally available and abundant which makes it easy and affordable to obtain [6], therefore, people in the low-income bracket can afford to acquire their own houses. In addition, instead of burning agricultural waste which contribute to carbon emissions and air pollution, wastes may be used to produce enhanced soil blocks. Socially, earth construction uses existing local or easily transferable skills, avoiding the need for costly training, reducing displacement of labour and reducing societal or cultural disruption especially in LEDCs. Understanding of how agricultural waste fibres enhance soil block properties is therefore important to practitioners of earth construction to maximize the performance and sustainability advantages compared with binders. 
There are two important parameters that contribute to strength development of fibre enhanced blocks. These are; fibre content (the fraction of fibre in the soil) and the fibre aspect ratio (the ratio of length to diameter of the fibre). Most studies on the use of natural fibres for enhancement of soil blocks have focused on the fibre content, with few incorporating fibre lengths in their experimental design $[1,5,16,17]$. There is therefore a need to determine the aspect ratio of fibres that will produce the optimum strength when used for stabilising soil blocks. Fibre aspect ratio is the ratio of length to diameter of a fibre and is usually expresses as a single number greater than 1 . This study therefore investigates the effect of aspect ratio of three different natural fibres derived from agricultural waste (coconut, bagasse and oil palm) on the mechanical properties of soil blocks.

\section{Materials and Methods}

An experimental study was conducted by using agricultural waste (coconut husk, bagasse and oil palm fruit) fibres as stabilising materials in the production of soil blocks. For this purpose, a local soil obtained from Sunyani town of Brong Ahafo region in Ghana was used for the production of the blocks. The properties of the soil are reported in Table 1.

Table 1: Properties of soil

\begin{tabular}{lc}
\hline Properties & Values \\
\hline Proctor test & \\
$\quad$ Optimum moisture content $(\%)$ & 18.0 \\
$\quad$ Maximum dry density $\left(\mathrm{Mg} / \mathrm{m}^{3}\right)$ & 1.78 \\
Atterberg limits & \\
$\quad$ Liquid limit LL (\%) & 13.3 \\
$\quad$ Plastic limit PL (\%) & 17.2 \\
$\quad$ Plasticity index PI (\%) & 13.9 \\
Particle size distribution & \\
$\quad$ Gravel $(>2 \mathrm{~mm})(\%)$ & 12 \\
Sand $(2-0.063 \mathrm{~mm})(\%)$ & 46 \\
$\quad$ Silt $(0.063-0.002 \mathrm{~mm})(\%)$ & 28 \\
Clay $(<0.002 \mathrm{~mm})(\%)$ & 14
\end{tabular}




\section{Organic content}

Content $(\%)$

$p H$

Value

7.33

The soil has a liquid limit of $13.3 \%$ and a plasticity index of $13.9 \%$ and hence could be classified as low plasticity clay soil (CL) according to BS1377 [18]. The optimum moisture content (OMC) for the soil without stabilisation was obtained by using a Standard Proctor mould [18] and was $18 \%$, the maximum dry density (MDD) was $1.78 \mathrm{Mg} / \mathrm{m}^{3}$. The particle size distribution curve is shown in Figure 1. The soil has pH value of 7.33 which means the soil is neutral (between acidic and alkaline) according to Soil survey division staff 'Soil survey manual' [19]. Chemical element/composition of the soil was determined through inductively coupled plasma-atomic emission spectrometry (ICP-AES) analysis method and the result is presented in Table 2.

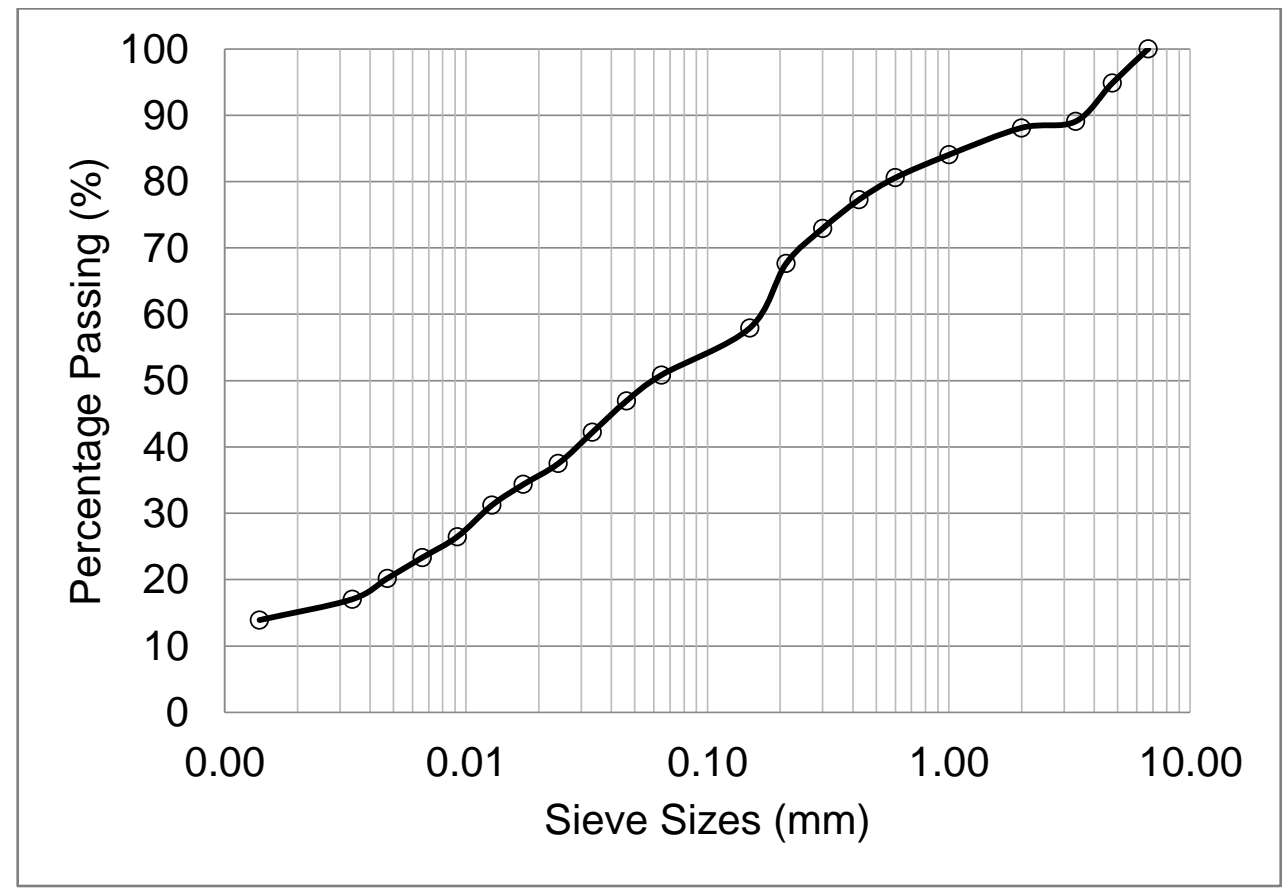

Figure 1: Particle Size Distribution of the Experimental Soil

Table 2: Chemical composition of soil

\begin{tabular}{ll}
\hline $\begin{array}{l}\text { Element/ Concentration }(\mathrm{mg} / \mathrm{kg}) \\
\text { compound }\end{array}$ & \\
\hline
\end{tabular}




\begin{tabular}{lc}
\hline $\mathrm{Al}^{3+}$ & 0.06 \\
$\mathrm{Ca}^{2+}$ & 44.0 \\
$\mathrm{SiO}_{2}$ & 0.06 \\
$\mathrm{~K}$ & 3.88 \\
$\mathrm{Zn}$ & 0.86 \\
$\mathrm{~Pb}$ & 0.10 \\
$\mathrm{Fe}$ & 1.038 \\
$\mathrm{Mg}^{2+}$ & 14.8 \\
$\mathrm{Cl}^{-}$ & 18.99 \\
$\mathrm{PO}_{4}{ }^{3-}$ & 6.17 \\
$\mathrm{SO}_{4}{ }^{2-}$ & 20.0 \\
\hline
\end{tabular}

Bagasse fibre was obtained from sugar cane residue at a local sugarcane alcohol distillery mill in Somanya, the coconut fibre was obtained from the husk of coconut fruit from coconut vending points at Cape Coast and oil palm fibre was obtained from a palm oil extraction plant in Kumasi, Ghana. The by-products were soaked in water for at least $48 \mathrm{hrs,} \mathrm{mechanically} \mathrm{beaten}$ and the fibres extracted and dried. The images of the fibres and SEM of each fibre type is shown in Figure 2. SEM images of single fibre were determined with JSM-6100 scanning microscope at 35x magnification for each fibre type (Figure 2).

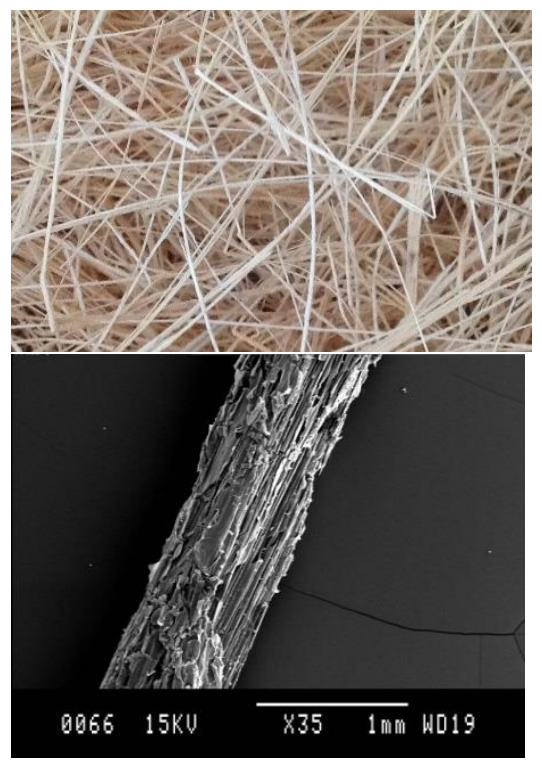

a. Bagasse fibre

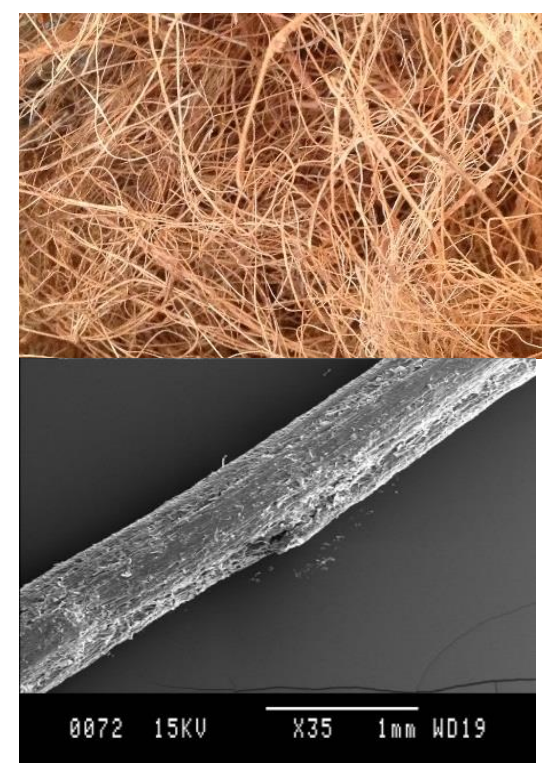

b. Coconut fibre

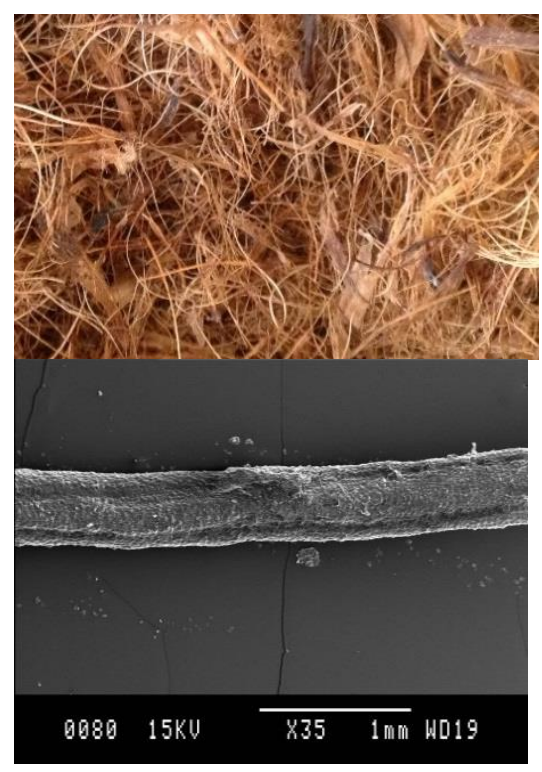

c. Oil palm fibre

Figure 2: Photographs and SEM Micrographs of the Types of fibre tested 
One hundred fibres (from each type) were randomly selected for determining the length and diameter. A compound light Microscope (Leitz HM-LUX3) of 25x magnification with a graticule eye piece was used for the measurement of diameter while a steel rule was used to measure the length. The fibre diameter was measured at five points evenly along each length. The distribution of the measurements are shown in Figure 3 and display a generally normal distribution with only the oil palm displaying any marked tapering. The nominal diameter determined by taking the mean of these measurements for each fibre type and required fibre lengths were obtained by multiplying the nominal diameter by the required aspect ratio. These are shown in Table 3. It should be noted that, as there are a range of diameters of fibre present in each block, the corresponding aspect ratio will also vary with the same relative standard deviation as quoted for diameter.

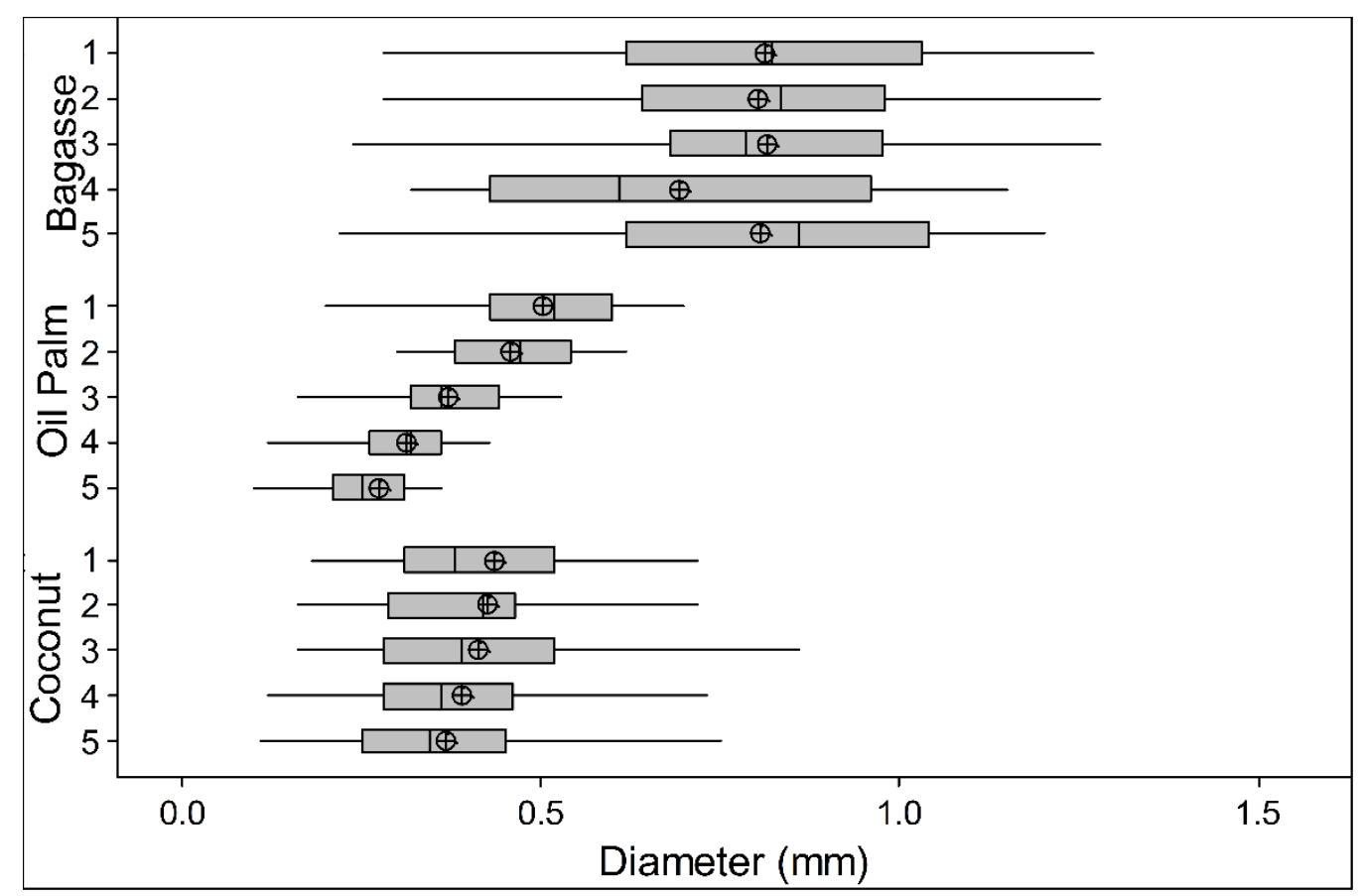

Figure 3: Distribution of Fibre Diameter Measurements Box plots represent the range of fibre diameter

Table 3: Required length of fibre for aspect ratios 


\begin{tabular}{|c|c|c|c|c|c|c|c|c|c|}
\hline \multirow[b]{2}{*}{ Fibre Type } & \multirow{2}{*}{$\begin{array}{c}\text { Mean Diameter } \\
(\mathrm{mm})\end{array}$} & \multirow{2}{*}{$\begin{array}{c}\text { Std } \\
\text { Dev } \\
(\mathrm{mm})\end{array}$} & \multirow{2}{*}{$\begin{array}{l}\text { RSD } \\
(\%)\end{array}$} & \multirow{2}{*}{$\begin{array}{l}\text { Normality } \\
\text { (p-value) }\end{array}$} & \multicolumn{5}{|c|}{ Aspect Ratio } \\
\hline & & & & & 25 & 50 & 75 & 100 & 125 \\
\hline Coconut & 0.40 & 0.17 & 42.5 & 0.065 & - & $20 \mathrm{~mm}$ & $30 \mathrm{~mm}$ & $40 \mathrm{~mm}$ & $50 \mathrm{~mm}$ \\
\hline Bagasse & 0.78 & 0.19 & 23.8 & 0.270 & - & $40 \mathrm{~mm}$ & $60 \mathrm{~mm}$ & $80 \mathrm{~mm}$ & $100 \mathrm{~mm}$ \\
\hline Oil Palm & 0.38 & 0.08 & 23.7 & 0.075 & $10 \mathrm{~mm}$ & $19 \mathrm{~mm}$ & $28 \mathrm{~mm}$ & $38 \mathrm{~mm}$ & - \\
\hline
\end{tabular}

Enhanced soil blocks of $290 \times 140 \times 100 \mathrm{~mm}$ were made with soil and $1 \%$ fibre by weight as this was the maximum fibre content recommended by previous studies [8, 20, 21] The fibres were cut to aspect ratios of $25,50,75,100$ and 125, which was limited by the fibre lengths available. The required quantity of the materials (soil, fibres and water) were weighted. The soil was first spread on a platform, then the fibre was spread on soil and turned over and over till a uniform mixture was obtained. Water was sprinkled on the soil-fibre mixture and turned over and again to obtained uniform mix. The blocks were made with pressure gauge hydraulic block making machine with a constant pressure of 100 bar. The blocks were sun dried at an average temperature of $27^{\circ} \mathrm{C}$ and relative humidity of $72 \%$ for 21 days (Figure 4) before testing.

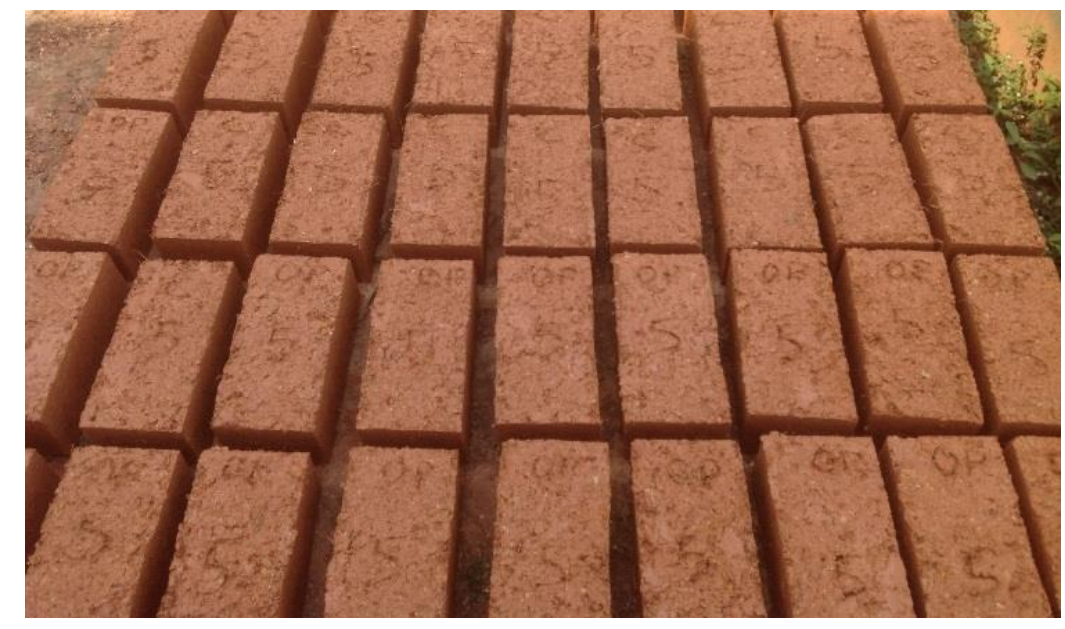

Figure 4: Drying of Soil Blocks

Compressive and tensile splitting tests were conducted to determine the mechanical properties of the blocks. The compressive test was conducted in accordance BS EN 771-1 [22]. A CONTROLS 50-C46G2 testing machine with maximum capacity $2000 \mathrm{KN}$ was used for 
conducting the test. The load was applied at a rate of $0.05 \mathrm{~N} / \mathrm{mm}^{2} / \mathrm{s}$ until the block failed, the load at which the blocks failed was recorded and maximum compressive stress was calculated.

The tensile splitting test was conducted in accordance with BS EN 12390-6 [23] with the testing machine and splitting jig which were placed centrally above and below the block. The load was applied continuously at a study rate of $0.05 \mathrm{~N} / \mathrm{mm}^{2} / \mathrm{s}$ up to failure of the block and tensile splitting strength calculated according to the standard.

\section{Results and Discussion}

\subsection{Effect of fibre aspect ratio on compressive strength}

The details of compressive strength test results of the enhanced soil blocks are reported in Table 4. Figure 5 summarises the compressive strength tests results for the fibre aspect ratios tested. It can be seen that for coconut fibre, the increase of fibre aspect ratio up to 125 increased the compressive strength by about $26 \%$ compared to the aspect ratio of 50 . Oil palm fibres show a continual increase up to 100 which is the maximum possible for this fibre, resulting in an increase of $14 \%$ over a ratio of 50 and $19 \%$ over a an aspect ratio of 25 , the smallest aspect ratio tested. Baggasse fibres displayed an optimum aspect ratio of 100 with a $32 \%$ improvement on the initial aspect ratio of 50 . 


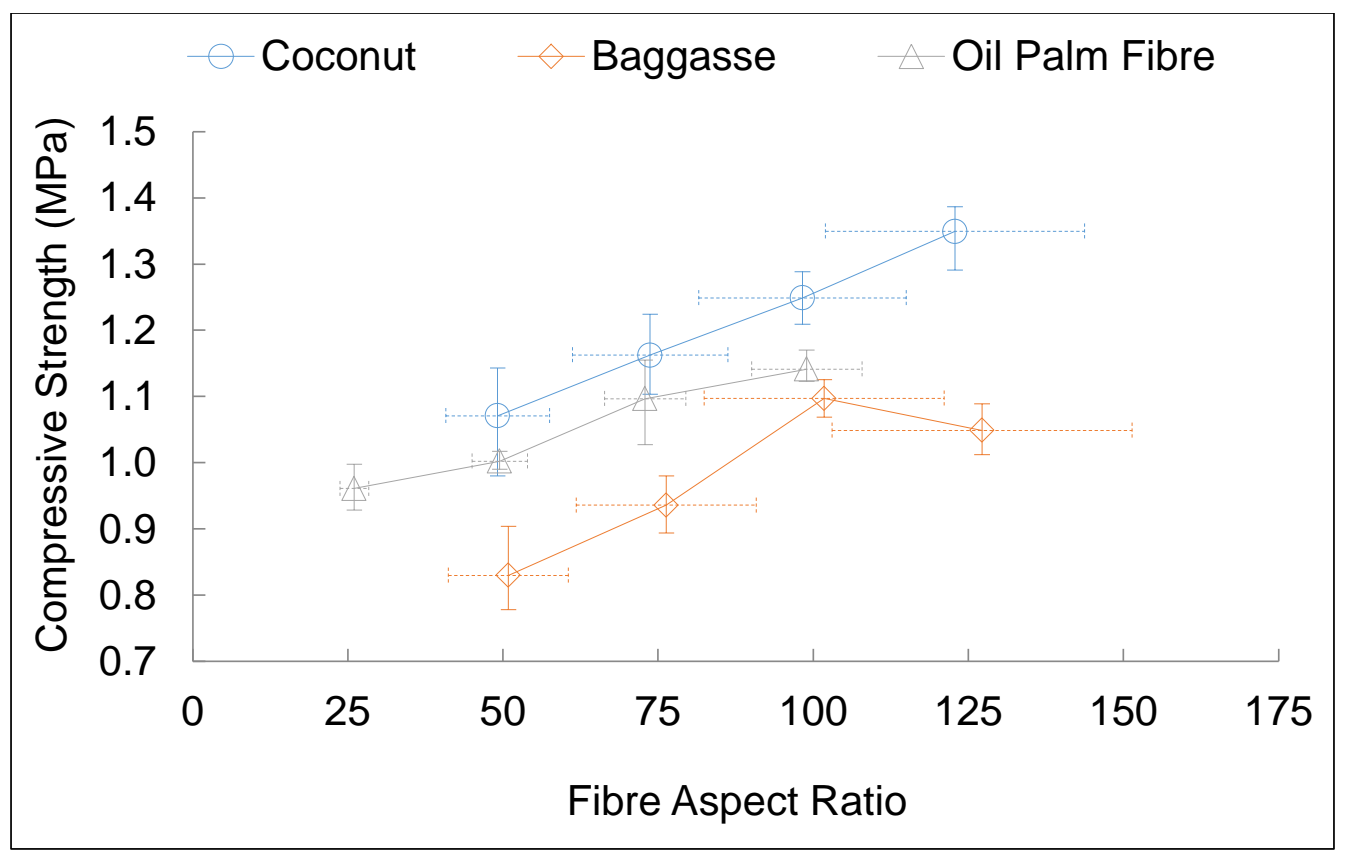

Figure 5: Compressive Strength Variation with Fibre Aspect Ratio

Vertical error bars represent the range of values found. Dotted horizontal error bars represent 1 standard deviation in fibre aspect ratio found in the block due to variations in fibre diameter. 
Table 4: Compressive and Tensile Strength Test Result

\begin{tabular}{|c|c|c|c|c|c|c|c|c|c|c|c|c|c|c|c|c|c|c|}
\hline \multirow[b]{2}{*}{$\begin{array}{l}\text { Aspect } \\
\text { Ratio }\end{array}$} & \multicolumn{3}{|c|}{ Coconut } & \multicolumn{3}{|c|}{ Bagasse } & \multicolumn{3}{|c|}{ Oil palm } & \multicolumn{3}{|c|}{ Coconut } & \multicolumn{3}{|c|}{ Bagasse } & \multicolumn{3}{|c|}{ Oil palm } \\
\hline & Value & Mean & SD & Value & Mean & SD & Value & Mean & $\mathrm{SD}$ & Value & Mean & $\mathrm{SD}$ & Value & Mean & SD & Value & Mean & SD \\
\hline \multirow[b]{5}{*}{25} & - & \multirow{5}{*}{-} & \multirow{5}{*}{-} & - & \multirow{5}{*}{ - } & \multirow{5}{*}{-} & 0.94 & \multirow{5}{*}{0.96} & \multirow{5}{*}{0.03} & - & \multirow{5}{*}{-} & \multirow{5}{*}{-} & - & \multirow{5}{*}{-} & \multirow{5}{*}{-} & 0.28 & \multirow{5}{*}{0.25} & \multirow{5}{*}{0.02} \\
\hline & - & & & - & & & 0.98 & & & - & & & - & & & 0.25 & & \\
\hline & - & & & - & & & 0.96 & & & - & & & - & & & 0.24 & & \\
\hline & - & & & - & & & 1.00 & & & - & & & - & & & 0.25 & & \\
\hline & - & & & - & & & 0.93 & & & - & & & - & & & 0.23 & & \\
\hline \multirow[b]{5}{*}{50} & 1.12 & \multirow{5}{*}{1.07} & \multirow{5}{*}{0.07} & 0.78 & \multirow{5}{*}{0.83} & \multirow{5}{*}{0.05} & 0.99 & \multirow{5}{*}{1.00} & & 0.20 & & & 0.19 & & & 0.25 & & \\
\hline & 1.01 & & & 0.81 & & & 1.02 & & & 0.17 & & & 0.20 & & & 0.27 & & \\
\hline & 1.14 & & & 0.82 & & & 1.00 & & & 0.15 & & & 0.22 & & & 0.25 & & \\
\hline & 0.98 & & & 0.90 & & & 1.00 & & 0.01 & 0.18 & 0.18 & 0.02 & 0.20 & 0.21 & 0.01 & 0.26 & 0.26 & 0.01 \\
\hline & 1.10 & & & 0.84 & & & 1.01 & & & 0.17 & & & 0.21 & & & 0.27 & & \\
\hline & 1.10 & & & 0.90 & & & 1.16 & & & 0.25 & & & 0.25 & & & 0.30 & & \\
\hline & 1.17 & & & 0.98 & & & 1.12 & & & 0.22 & & & 0.23 & & & 0.28 & & \\
\hline & 1.12 & & & 0.89 & & & 1.03 & & & 0.23 & & & 0.20 & & & 0.27 & & \\
\hline & 1.19 & 1.16 & 0.05 & 0.93 & 0.94 & 0.04 & 1.05 & 1.10 & 0.05 & 0.23 & 0.24 & 0.02 & 0.24 & 0.23 & 0.02 & 0.29 & 0.29 & 0.01 \\
\hline 75 & 1.22 & & & 0.98 & & & 1.12 & & & 0.26 & & & 0.22 & & & 0.30 & & \\
\hline & 1.25 & & & 1.07 & & & 1.13 & & & 0.25 & & & 0.29 & & & 0.33 & & \\
\hline & 1.23 & & & 1.12 & & & 1.15 & & & 0.28 & & & 0.27 & & & 0.31 & & \\
\hline & 1.27 & & & 1.13 & & & 1.17 & & & 0.26 & & & 0.26 & & & 0.29 & & \\
\hline & 1.21 & 1.25 & 0.03 & 1.10 & 1.10 & 0.03 & 1.14 & 1.14 & 0.02 & 0.24 & 0.26 & 0.01 & 0.28 & 0.28 & 0.01 & 0.27 & 0.30 & 0.02 \\
\hline 100 & 1.29 & & & 1.07 & & & 1.12 & & & 0.25 & & & 0.29 & & & 0.30 & & \\
\hline & 1.36 & & & 1.05 & & & - & & & 0.26 & & & 0.26 & & & - & & \\
\hline & 1.29 & & & 1.01 & & & - & & & 0.29 & & & 0.25 & & & - & & \\
\hline & 1.36 & & & 1.08 & & & - & & & 0.32 & & & 0.28 & & & - & & \\
\hline & 1.35 & 1.35 & 0.04 & 1.02 & 1.05 & 0.03 & - & - & - & 0.25 & 0.29 & 0.03 & 0.26 & 0.26 & 0.01 & - & - & - \\
\hline 125 & 1.39 & & & 1.09 & & & - & & & 0.31 & & & 0.27 & & & - & & \\
\hline
\end{tabular}


The result of coconut fibre is similar to the result of a study conducted by Yalley [21], which coconut fibre enhanced concrete obtained the highest compressive strength with a fibre aspect ratio of 125. It must however be noted that the actual theoretical maxima may be higher still, but is constrained by the fibre lengths available. For bagasse fibre, there was a 5\% (for fibre aspect ratio125) decrease after the optimum compressive strength was achieved at a fibre aspect ratio of 100. The magnitude of the effect of fibre aspect ratio on the compressive strength of soil blocks is in the same order as that found for changing the fibre content. Furthermore, not all fibre types will produce continually increasing compressive strength with increase of fibre length, making the determination of the optimum aspect ratio an important step in the specification of enhanced soil blocks.

It is likely that the increase in strength caused by longer fibres is due to greater adhesion of the fibre to the matrix caused either by greater friction between the fibre and the matrix or looping of the fibre in the matrix. Longer fibres will also be more effective as the block matrix fails, as longer fibres will form longer bridges across cracks and are less likely to be anchored in a part of the matrix that has separated from the rest of the block.

Previous studies concentrating on fibre quantity have commented that reductions in performance occur when fibres begin to knot together [15] resulting in lost cohesion with the soil [24] or break-up of the soil matrix [8] causing the soil-fibre composite to weaken. It is likely that these factors also cause blocks with very long flexible fibres to reduce in strength. Other potential causes are that very long fibres may fail to disperse or distribute evenly within the matrix [8] or form a multifilament structure [25] in soil during mixing and therefore increase the local porosity of the reinforced soil blocks. 


\subsection{Effect of fibre aspect ratio on tensile strength}

Table 4 gives the details of the tensile strength tests as well as compressive strength results while Figure 6 summarises the tensile strength results. The trend of the results is similar to that of the compressive strength. Coconut fibres have a rising strength until the longest samples available with an AR of 125. Similarly, oil palm rises until its maximum AR of 100 and bagasse displays an optimum of an AR of 100 . The increase in tensile strength was up to $61 \%, 24 \%$ and $20 \%$ respectively for coconut, bagasse and oil palm fibres. Failure of the fibre enhanced soil blocks was with multiple finer cracks with a gradual failure resembling a ductile material which agrees well with Cai, Shi [26].

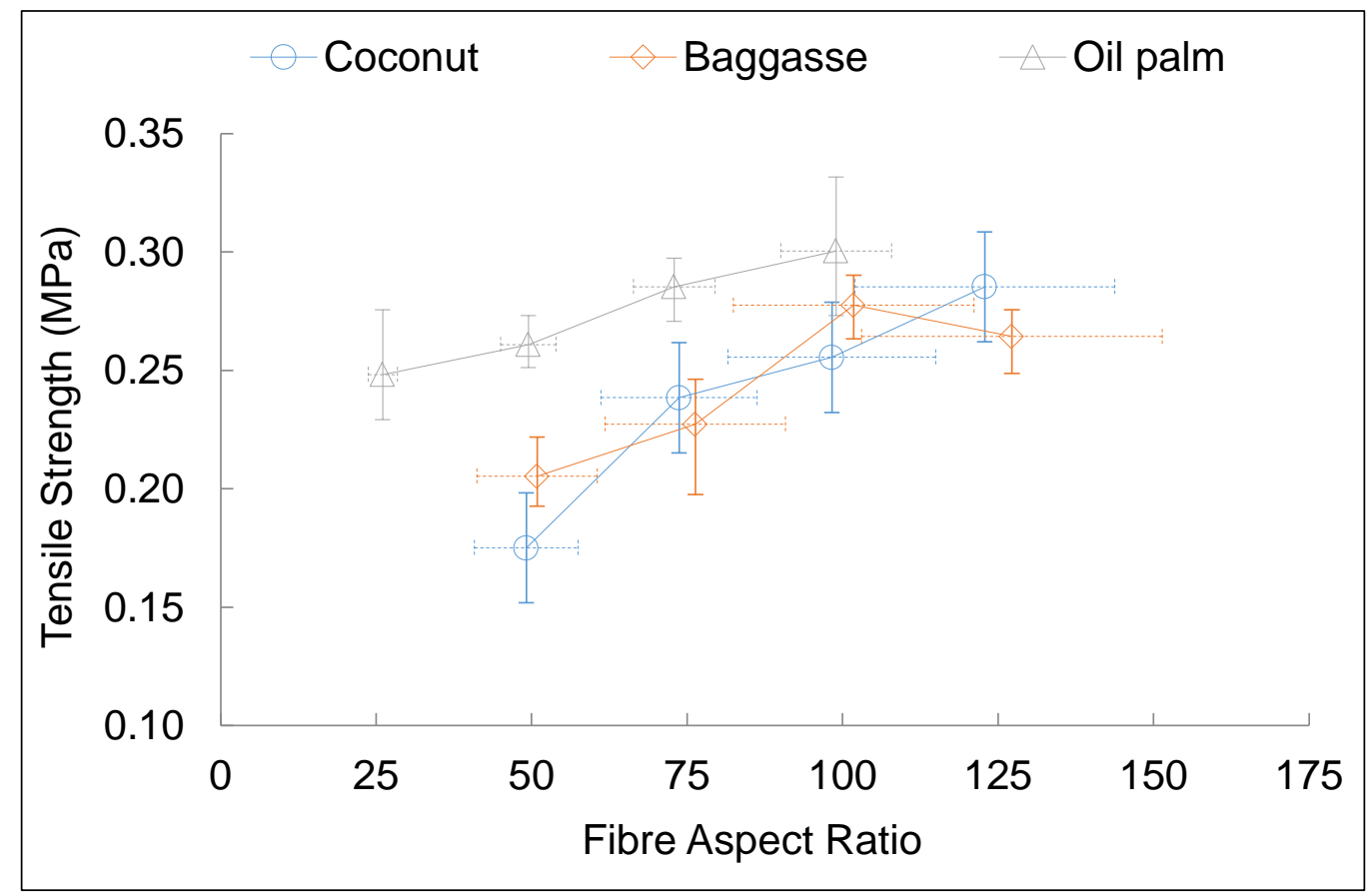

Figure 6: Tensile Splitting Strength Variation with Fibre Aspect Ratio Error bars as described in Figure 5

Upon removal from the testing machine, it became apparent that although the blocks were split into two, the two parts were still held together by the fibres (Figure 7). This indicates that blocks 
will fail slowly rather than suddenly and will still hold a load (albeit with considerable deformation) sometime after failure.

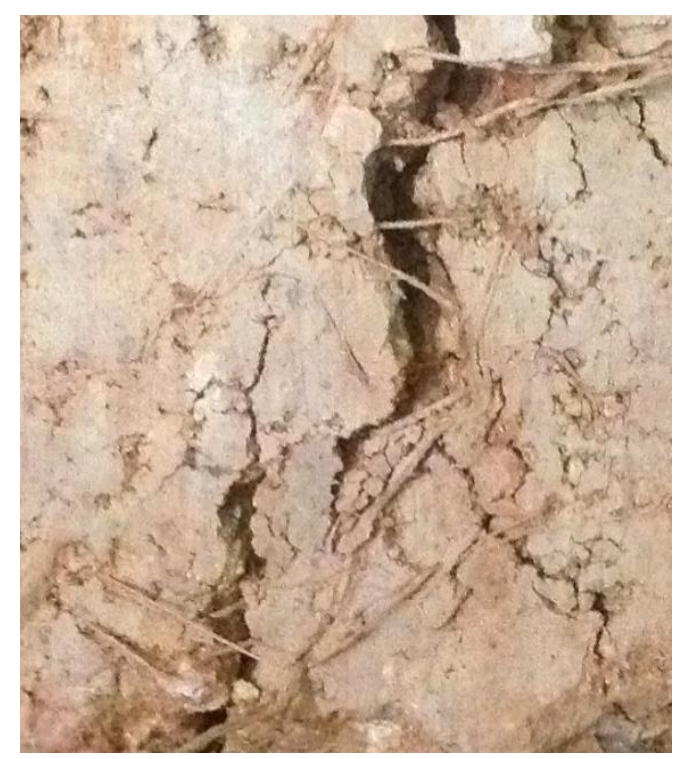

Figure 7: Split Block Held Together by Fibres

\subsection{Relationship between compressive and tensile strengths effect on fibre aspect ratio}

Inspection of the compressive and tensile results shows that in both results bagasse fibre recorded an optimum strength at fibre aspect ratio 100 while coconut and oil palm fibres obtained peak strength at fibre aspect ratios 125 and 100 respectively. Figure 8 summarises the relationship between the compressive and splitting tensile strength of the enhanced soil blocks for the fibres and aspect ratios used. The results indicate a strong linear relationship between compressive and tensile strengths of the enhanced soil blocks with coefficients of determination $\left(\mathrm{R}^{2}\right)$ of $0.939,0.978$ and 0.998 for coconut, bagasse and oil palm fibres respectively, though these are based on the means of a range of data. 


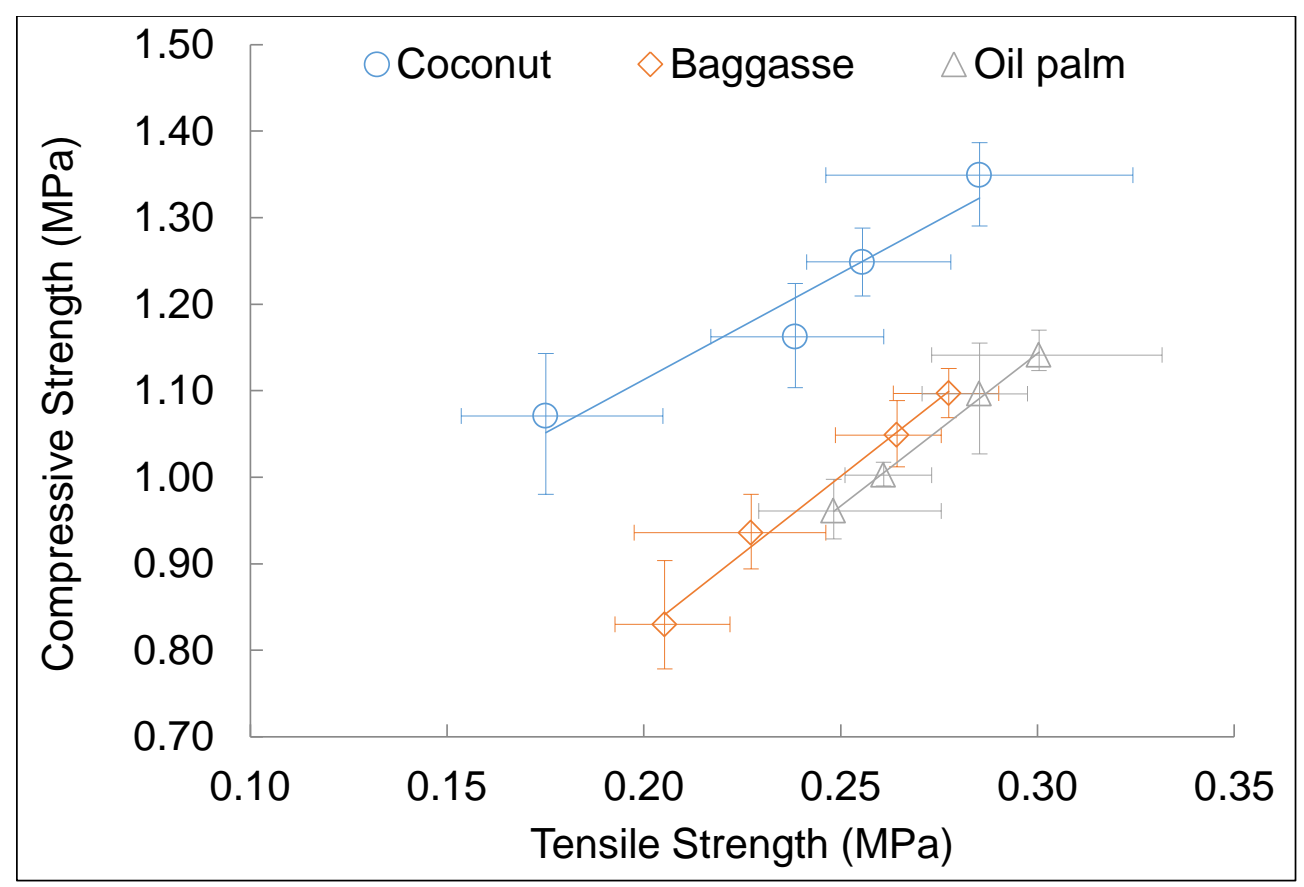

Figure 8: Relationship Between Compressive and Tensile Strengths of Fibre Aspect Ratio Error bars represent the range of results obtained

The relation of compressive strength to tensile strength is given by a factor of 2.46, 3.58 and 3.53 for coconut, bagasse and oil palm fibres respectively. This agrees fairly well with a previous study which found compression to flexural/tensile ratios in the order of 4 [9].

\section{Conclusion}

In this paper, the effect of aspect ratio of three different agricultural waste fibres on the mechanical properties of soil blocks was investigated. The results obtained suggest that:

- The coconut fibre aspect ratio that could produce the maximum compressive and tensile strengths of soil blocks may be 125 or higher. In terms of linear dimension, it translates into length of $50 \mathrm{~mm}$ or higher of the coconut fibre. This produced about $25 \%$ improvement in compressive strength and more than half in tensile strength over the smallest fibre aspect ratio tested. 
- Bagasse fibre achieved an optimum compressive and tensile strengths at an aspect ratio of 100 , which in terms of length of the fibre is $80 \mathrm{~mm}$. This produced about $25 \%$ improvement over the smallest fibre aspect ratio for both compressive and tensile strengths.

- The highest available aspect ratio of 100 for oil palm fibre recorded the highest value for both compressive and tensile strengths. This aspect ratio was equivalent in length to 38 mm. There was about $20 \%$ improvement in peak compressive and tensile strengths over the smallest aspect ratio.

- There was a strong linear relationship between compressive and tensile strengths of the enhanced soil blocks for each of the fibre aspect ratio for each fibre type.

The study concludes that, in general, an increase in fibre aspect ratio has a positive effect on the strength of enhanced soil blocks. The fibre aspect ratio for all the fibre types produced a maximum strength at fibre aspect ratios of 100 and 125. This finding supports Halpin and Kardos [27] assertion that reinforcing fibers for composite materials should be equal to or greater than an aspect ratio of 100 . While this is generally true, it must be noted that not all fibre enhanced blocks will achieve an increased strength that the maximum aspect ratio as bagasse fibre obtained optimum compressive and tensile strengths at a slightly lower aspect ratio than the maximum. This implies that researchers and practitioners need to determine the optimum fibre aspect ratio to be used for stabilising soil blocks as well as the optimum fibre content in order to produce blocks that will provide the maximum strength for walling of houses. There are a good number of other agricultural waste fibres which have been the subject of studies into optimum fibre content. Further improvements in mechanical performance may be possible with 
consideration of aspect ratio for these fibres. Further studies could also consider investigating into the effect of fibre aspect ratio on the durability properties of soil blocks since this is another critical determinate of the engineering properties of soil blocks.

\section{Reference}

[1] Bouhicha M, Aouissi F, Kenai S. Performance of composite soil reinforced with barley straw. Cement \& Concrete Composites 2005;27:617-21, doi:10.1016/j.cemconcomp.2004.09.013.

[2] Demir I. An investigation on the production of construction brick with processed waste tea. Building and Environment. 2006;49(1):1274-8, doi:10.016/j.buildenv.2005.05.004.

[3] Achenza M, Fenu L. On earth stabilization with natural polymers for earth masonry construction. Materials and Structures 2006;39:21-7, DOI 10.1617/s11527-005-9000-0.

[4] Kolop R, Haziman WIM, Eng JW. Properties of Cement Blocks Containing High Content of Oil Palm Empty Fruit Bunches (EFB) Fibers. Malaysia: Universiti Tun Hussein Onn; 2010.

[5] Juárez C, Guevara B, Valdez P, Durán-Herrera A. Mechanical properties of natural fibers reinforced sustainable masonry. Construction and Building Materials. 2010;24:1536-41.

[6] Chan CM. Effect of Natural Fibers Inclusion in Clay Bricks: Physico-Mechanical Properties. International Journal of Civil and Environmental Engineering. 2011;3(1):51-7.

[7] Villamizar MCN, Araque VS, Reyes CAR, Silva RS. Effect of the addition of coal-ash and cassava peels on the engineering properties of compressed earth blocks. Construction and Building Materials 2012;36:276-86, doi.org/10.1016/j.conbuildmat.2012.04.056.

[8] Millogo Y, Morel J-C, Aubert J-E, Ghavami K. Experimental Analysis of Pressed Adobe Blocks Reinforced with Hibiscus Cannabinus Fibers. Construction and Building Materials. 2014;52:71-8. [9] Danso H, Martinson B, Ali M, Mant C. Performance characteristics of enhanced soil blocks: a quantitative review. Building Research \& Information. 2015:DOI: 10.1080/09613218.2014.933293. [10] Vasoya PJ. Studies on high performance cardo polymers. India: Saurashtra University: http://etheses.saurashtrauniversity.edu/479/1/vasoya pj thesis chemistry.pdf; 2007.

[11] Rodrigues EF, Maia TF, Mulinari DR. Tensile strength of polyester resin reinforced sugarcane bagasse fibers modified by estherification. Procedia Engineering. 2011;10:2348-52.

[12] Alavéz-Ramírez R, Montes-Garcia P, Martinez-Reyes J, Altamirano-Juarez DC, Gochi-Ponce Y. The use of sugarcane bagasse ash and lime to improve the durability and mechanical properties of compacted soil blocks. Construction and Building Materials. 2012;34:296-305, doi:10.1016/j.conbuildmat.2012.02.072.

[13] Al-Sakkaf YKA. Durability Properties of Stabilized Earth Blocks: Universiti Sains Malaysia; 2009. [14] Deboucha S, Hashim R. A review on bricks and stabilized compressed earth blocks. Scientific Research and Essays. 2011;6(3):499-506.

[15] Ismail S, Yaacob Z. Properties of Laterite Brick Reinforced with Oil Pal Empty Fruit Bunch Fibres. Pertanika Journal of Science and Technology. 2011;19(1):33-43.

[16] Aymerich F, Fenu L, Meloni P. Effect of reinforcing wool fibres on fracture and energy absorption properties of an earthen material. Construction and Building Materials 2012;27:66-72, doi:10.1016/j.conbuildmat.2011.08.008.

[17] Gaw B, Zamora S. Soil Reinforcement with Natural Fibers for Low-Income Housing Communities: Worcester Polytechnic Institute; 2011. 
[18] BS1377. Methods of test for soil for civil engineering purposes. Part 2: classification tests: British Standards; 1990.

[19] Soil survey division staff 'Soil survey manual'. Chapter 3, selected chemical properties. Soil conversation service. U.S. department of agriculture handbook 18. 1993.

[20] Obonyo E, Tate D, Sika V, Tia M. Advancing the Structural Use of Earth-based Bricks: Addressing Key Challenges in the East African Context. Sustainability. 2010;2:3561-71, doi:10.390/su2113561.

[21] Yalley PP. use of waste and low energy materials in construction. Germany: LAP LAMBERT Academic Publishing; 2012.

[22] BS EN 771-1. Methods of test for masonry units. Determination of compressive strength. European Standardn adopted by British Standards Institution: http://shop.bsigroup.com/ProductDetail/?pid=000000000030215378 2011.

[23] BS EN 12390-6. Testing hardened concrete. Tensile splitting strength of test specimens. European Standardn adopted by British Standards Institution: https://www.documentcenter.com/standards/show/BS-EN-12390-6; 2009.

[24] Medjo Eko R, Offa ED, Ngatcha TY, Minsili LS. Potential of salvaged steel fibers for reinforcement of unfired earth blocks. Construction and Building Materials 2012;35:340-6, doi.org/10.1016/j.conbuildmat.2011.11.050.

[25] Bentur A, Akers SAS. The microstructure and ageing of cellulose fibre reinforced cement composites cured in a normal environment. International Journal of Cement Composite, Lightweight Concrete, 11, (2), 1989, pp 93-97. 1989;11(2):93-7. DOI: 10.1016/0262-5075(89)90121-8.

[26] Cai Y, Shi B, Ng CWW, Tang C. Effect of polypropylene fibre and lime admixture on engineering properties of clayey soil. Engineering Geology 2006;87:230-40, doi:10.1016/j.enggeo.2006.07.007. [27] Halpin JC, Kardos JL. The Halpin-Tsai equations: a review. Polymer Engineering Science.

1976;16:344-52. 